\title{
Learning Analytics Mobile Application for the Bucharest University of Economic Studies' Students
}

\author{
Anca IANCU, Daniel-Mihai IONESCU \\ Bucharest University of Economic Studies, Romania \\ anca.iancu93@gmail.com,daniel_mihai_ionescu@yahoo.com
}

Learning analytics refers to improving the educational process by providing feedback and involving all the stakeholders. It is a very useful method with positive effects on both students and teachers. In ASE, the idea of learning analytics is not very well shaped, so development is needed on this side. This article proposes a learning analytics app for better exploitation of SIMUR database content in order to improve the educational processes in the university. Keywords: Learning Analytics, Educational Process Improvement, Students, Feedback

\begin{abstract}
1 Introduction
In the last years there was an increasingly interest in personal and professional development and acquirement of as many information as possible, especially by development of alternative ways of study like online courses or training sessions for free. It is harder to keep the students interested when they have access to a lot of information interactively presented. So, it was necessary to develop a solution to provide proactive feedback and predict success or failure of a student in order to guide the learning process in such a way that offer the necessary information and maintain the students focused.
\end{abstract}

This methodology called learning analytics implies the measurement and analysis of data about learners aimed at optimizing the process of learning, providing better information and a deep understanding of the field of interest for those involved. [1]

Of course, there are many other ways to solve the problems in this area, reforming the learning process and introducing interactive teaching methods being only a small part of what can be done. However, it is very important to know the main cause and the factors that led to that problem in order to solve it, so learning analytics came to show the elements essentially to know and the main directions to the solution, making it the most suitable response. Just as it happens in any methodology, there are some limitations for learning analytics. According to [2], some of the limitations for learning analytics are:

- Information belongs to different systems and there is not a unique system;

- Education-technology industry has not enough standards and is not cooperating;

- The governments don't focus on structures and focus on content;

- Researchers don't focus on the processes in an ecosystem and focus on algorithms or teaching;

- The target of the tools and reports is not the professional capital and capacity building;

- In the relation between governments, school, leadership, teachers, students and the community does not exist enough trust.

Taking these into account, there is a necessity to develop a solution to solve the main problems connected to learning process. Because of limitations of learning analytics, especially regarding a unified education system for all the institutions, we have focused only on students from Bucharest University of Economic Studies by developing an app for their needs. This software solution is designed to communicate with SIMUR database and to provide some key functionalities for every student, beyond their year of study or their faculty. Learning analytics means various benefits for all stakeholders so this application provides several reports and predictions to help both students and teachers by improving the learning process.

As innovations, the current software solution comes with specific elements in order to sup- 
port students by providing methods of efficient time planning such as Gantt charts or predictions for specific facts as chances for a scholarship.

\section{Related Work}

Learning analytics became an important topic when referring to teaching and learning process, to students' success and to new methods of teaching and how useful they are. Frequently, papers related to learning analytics are focusing on what students will know at the end of the learning process and the elements that have an influence to this aspect, but, in order to understand and to use at the proper level the power of learning analytics a deeper look is needed.

An analysis of data in the teaching process was done even before the widespread use of technology in order to obtain a feedback about the work done in the previous period, these calculations being done by hand. After that, learning analytics came to automate the process and to take care of all the data.

Learning analytics has contributed very much in growth of effectiveness in the education field. Research has begun to be more intense in the learning analytics community after the appearance of massive online courses, online video-based learning, educational applications and the high availability of all kinds of computing devices. In the last years, the learning analytics community has been in an attempt to find coherence which has surely appeared in 2015. Throughout this period there were recorded some interesting trends in this field. It has made the transition from counting events in clickstreams and reporting their percentage to establishing correlations and developing theoretical models. After this transition, it was created an environment where humans and machines work together in an efficient way.

- There are several emerging major trends for learning analytics such as [3]:

- Expanding the data sources for learning analytics;

- The types of data used by researchers, teaching and learning being multimodal processes, which include various processes happening at the same time;

- The depth of the analysis, the community making important progresses in the algorithms which are used for analyzing learning data;

- The increasing complexity and applicability of research.

- In [4] a reference model for learning analytics is proposed, which is built on the following four dimensions:

- What?, it refers to the type of data

- Who?, it refers to stakeholders like students or teachers with various needs

- Why?, it refers to objectives including monitoring or analysis

- How?, it refers to four techniques like namely statistics or data mining

Learning analytics design patterns means a research orientation about the "how?" dimension of the above model. It is important to use design patterns for developing an efficient and useful learning analytics tool. Another opportunity of research related to the "how?" dimension of the model is the evaluation of the learning analytics tools. There are some things that are important for making an effective evaluation such as the purpose of the evaluation. It is important for evaluators to define good indicators, metrics and consider collecting qualitative data, which must be in relation with quantitative evaluation (where it is possible). [4]

Most of the research on this area reveals that the main points regarding learning analytics are related to providing feedback, extend and automate the collecting of data and involving more people with different roles in this action. According to [5], those three key institutional considerations when developing a learning analytics approach in an analytics ready context are:

a. Provision of data - data from different sources (special care should be paid to homogenization of data);

In these days, everything can be a source of data and can be used accordingly. An interesting approach should be considered that of Dragan Gašević and Mykola Pechenizkiy [6] 
who think that is necessary to include data obtained from social networks in learning analysis. According to them, data from "social networks can be extracted and processed with different metrics commonly used in social network analysis" but they are not enough because they do not offer sufficient insight into the content that has been communicated via social networks and need to be associated with other category of data.

The idea of automation the provision of data and to enlarge the data source is also sustained by the same authors along with Siemens in another paper [7] but they warns us to take care in this step at the process of teaching and learning itself because the solely focus on outcomes can have negative consequences even though it may seem promising to automate many measurements and predictions about learning and teaching.

b. Interpretation and visualization make data useful and present it in a meaningful way;

The main aspect in this step is to know exactly what the purpose of the learning analytics is. Of course, it is not an easy task to interpret all the data in such a way that all the stakeholders to be satisfied but knowing the exact role of the analysis and focusing on it ensure the achieving of the objectives. This aspect should not be considered as a reason to involve as less people as possible, contrariwise all the people involved in the learning and teaching process need to take part in this action. [6]

c. Actioning insights - turn insights into actions.

As the result of the learning analytics we can take into consideration the solutions found in order to improve the teaching and learning process and students' success and motivation by giving the proper feedback and guiding them to the right path.

The result of learning analytics need to be considered as an early warning for teachers because they have a better overview on the students' performance and can support those students who are at risk of dropout or those who have gaps in their knowledge. However, an interesting approach is presented by
Gašević, Dawson and Siemens. [7] They consider that comparing each student with the class average is not always the best solution because students who had strong academic standing will consider that they did well in class by being above average even though their results are well below their previous academic performance and goals set before enrolling into the class. On the other hand, the same effect can be reflected on underperforming students who will underestimate themselves although it may in some cases have exceeded past performance. As a solution to this problem, the authors consider that "it is essential to consider instructional, learning and sense making benefits for learning" and to take as a foundation for learning analytics the distributed cognition and self-regulated learning.

To summarize, learning analytics is an important part of improving the learning and teaching process, helping both students and teachers, but also other stakeholders to gain new information. Providing personalized feedback for every student, supporting them to confront with real world issues, establishing correlations between various data and developing theoretical models are just a small part of what learning analytics means.

\section{The design of a Learning analytics app for ASE's students}

Before starting to design an application of learning analytics for students from Bucharest University of Economic Studies, we reviewed the technological options. We decided that for the development of the app a REST server built in Java is required. Regarding the application architecture, we decided to define a hybrid mobile application, given the diversity of operating systems for mobile devices. The app is connected to the database of ASE Bucharest, in order to obtain the following data: grades, educational plans and users and passwords for student accounts.

\subsection{The Development Platform}

A hybrid application is an application that combines elements of a native application and 
of a web application being platform-independent. From the existing platforms available to build such applications, we chose PhoneGap. This is a platform based on HTML and JavaScript which can be used for creating a hybrid mobile application. A PhoneGap app allows access to certain elements of the mobile device via JavaScript code using HTML5 and CSS3 for graphical interface. If we want to notice a disadvantage of this platform, this refers to the fact that PhoneGap uses browser functionality which makes applications developed using this platform to be less rapid than native applications. [8]

Jersey is a framework for developing restful web services using Java. The main advantage of this framework refers to the multitude of features offered while it remains open-source. Jersey offers a simple construction of a restful web server. [9] REST principle refers to the fact that clients and server may interact in a complex way without the client knowing anything about the server and the resources available to it. The only rule is that between them to be a communication protocol and exchange of information. A web server is generally used for machine to machine communication, most often to transfer formats that can be interpreted by machines as XML and JSON. [10]

\subsection{Application architecture}

The main source of data for application of learning analytics is the database from ASE Bucharest which contains information about students and subjects studied. The web server is connected to the database to extract the necessary information in processing.

Regarding architecture, the server written in Java accepts HTTP GET and POST requests.

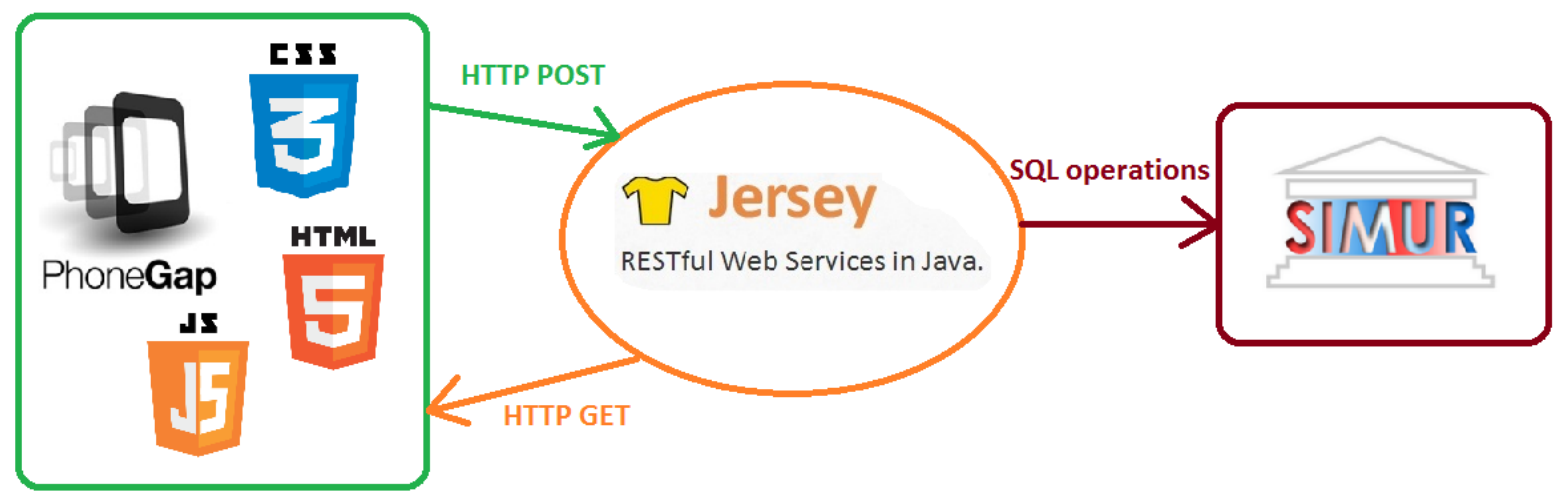

Fig. 1. Application's architecture

The mobile application helps students from ASE by offering numerous functionalities in order to improve their performance and provide feedback relative to the progress of each student. Including learning analytics technology, application responds particularly to the needs of students of this university focusing on what they need and not on some reports which are not personalized. The application was designed to be focused around the assessment activity of students providing for each mark obtained, reports and future projections on performance helping the student to meet his goals. Regarding aid to teachers, application has a way of feedback from students. In the next section we will cover the functionalities of this application. 
Table 1. The Main Application's Functionalities

\begin{tabular}{|l|l|}
\hline Functionality & Short description \\
\hline Report following evaluation & $\begin{array}{l}\text { Show the student situation in the group, } \\
\text { graphic distribution of grades and a compari- } \\
\text { son with previous semesters. }\end{array}$ \\
\hline Forecast exam score & $\begin{array}{l}\text { Report that makes a forecast of the grade re- } \\
\text { ceived by student at final examination de- } \\
\text { pending on the results of ongoing evaluation } \\
\text { such as homework or tests. }\end{array}$ \\
\hline Forecast ranking in the faculty & $\begin{array}{l}\text { Report that shows the possibility that a stu- } \\
\text { dent to get a state subsidized place, to get a } \\
\text { normal or merit scholarship or to benefit from } \\
\text { a place in university dormitories in the next } \\
\text { period. }\end{array}$ \\
\hline Analysis solving assigned tasks & $\begin{array}{l}\text { The application analyzes the moment when it } \\
\text { is loading the solutions for assigned tasks } \\
\text { considering the deadline for them and mak- } \\
\text { ing suggestions based on it. }\end{array}$ \\
\hline Management of feedback questionnaires & $\begin{array}{l}\text { To view the grade each student must com- } \\
\text { plete a feedback questionnaire that comes to } \\
\text { help the teacher. }\end{array}$ \\
\hline
\end{tabular}

Regarding the first functionality, the app having access to data from all students, it achieves a ranking of students per group, identifying the position of the current student (who is currently logged in). This is possible by accessing the data related to students and completing a report. Besides this information the student can also see a chart with distribution of grades for students in the group to which it belongs. The application also identifies the current week number accessing information related grades from the same week of previous semesters calculating the overall average mark obtained until the identified moment and making a comparison between the previous averages and the current average. This is useful for the student to see their own route through the years of study and it can have an impact on his future motivation.

Regarding the second function of the application, in most cases the students do not pay so much attention to partial evaluation rather that to final evaluation. In order to determine them to understand the importance of those assessments and also to stimulate their interest to learn an automated tool was used, which is able to predict the final grade based on their performances during the semester and this is useful for all categories of students. Those who are motivated and get good grades will find out that their final mark will be in accordance with their effort. On the other hand, those who are less interested can benefit by receiving a warning about their potential bad future results. For achieving this prediction, we need to obtain the following information inside the application: durations of the current semester in weeks, all grades obtained at every partial assessment from the start of the semester until the current moment and the week in which those partial evaluations took place. The computation formula for this prediction is described as follows:

where:

$$
\mathrm{g}_{\mathrm{f}}=\left(\mathrm{g}_{\mathrm{p}}+\mathrm{nopp}_{\mathrm{pp}} * \overline{\mathrm{g}}\right) / \mathrm{nopr}+1
$$

$\mathrm{g}_{\mathrm{f}}=$ grade for final evaluation

(predicted)

$\mathrm{g}_{\mathrm{p}}=$ previous grade (grade from the

last partial assessment)

nopp $=$ number of previous periods

(number of weeks passed until getting $\mathrm{g}_{\mathrm{p}}$ grade)

$\overline{\mathrm{g}}=$ the average of all grades obtained until now)

nopr $=$ number of the remained periods 
from getting $g_{p}$ grade until the end of the semester

In order to demonstrate the functionality presented we will consider the following example: we assume that for a learning discipline there are three evaluations except the final one: two homework and a test. The first homework is evaluated in the fourth week, the second homework in the twelfth week and the test takes place in the eighth week. A student gets for the first homework a seven, the test is evaluated with a five and for the second homework he gets an eight. Applying the above formula, it is easy to see that after the first evaluation (first grade), the predicted grade for this student is 7 , the same as the grade get for the first homework. After the test, his predicted grade becomes 5.85. This fact is understandable because the decreasing of the student's interest in learning means a lower predicted grade. This can be a warning for the analyzed student that can determine an increasing in student's interest for learning. After the last partial assessment, the student gets an eight so the final grade is predicted at 7.1, this example proving the efficiency of the formula described.

A quite big interest of ASE's students is connected to the places in the university's dormitories, the places financed from the state budget or the number of merit or study scholarships. So, the third functionality of this app justifies its utility. By having access to the database, the application has historical data about the number of places financed from the state budget for the faculty at which student is registered, the number of places available in the university's dormitories for this faculty and also about the number of scholarships available. The app extracts the existing grades for all the students from that faculty at current time and using the computation formula for every area of interest making a ranking of all students on each of these areas.

The logged student can find out information about the possibility of obtaining a budget founded place, a place in one of the university's dormitories or the possibility of getting a scholarship by receiving from the app a feedback saying if the student is part of the beneficiaries or if he is at X places behind the last beneficiary. For this feedback form, the app extracts the grades of all students from the current faculty at current time and applies the computation formulas related to each area of interest, making a raking of students in each of these areas.

The fourth functionality is focused on the learning process throughout the semester and analyzes the moment when students chose to solve their tasks. Considering the deadline to solve each assignment, this app analyzes the upload time of each solution. So, if a student upload his paper in the first quarter of the available time, the software search in the curriculum for those learning subjects to be studied that are part of the same study department and it makes suggestions to that student to learn more about them. If the student uploads his paper in the last quarter of the available time, the app checks for the next homework uploaded by teacher and it builds a Gantt chart of activities which includes the entire period until deadline in order to offer to student a clearer view on the division of available time. Last functionality helps students through their teachers because the feedback received by each teacher is useful to improve the learning process in which the students are involved. As we have analyzed students that usually are not very open to feedback, the app compels them to do so, by making giving feedback a condition for visualizing each grade. This part of the application is a questionnaire that includes questions like "Was the given time enough to solve the requirements?" "What was the level of the questions (too difficult, too easy or medium)?" "There were demands that required unstudied information?" and so on.

By using this application, the students from Bucharest University of Economic Studies will be more willing to dedicate time to study because they will receive a regular feedback on their progress. Also, they will have access to interesting information in an interactive way about their future results and about the consequences of their grades. We believe that the application will be adopted by all stakeholders involved in the educational process in ASE. 


\section{Conclusions}

In this paper was presented how learning analytics can be implemented in ASE by creating an application which uses the information from SIMUR system with the purpose of making the educational process easier and friendlier for students. After using this app, students will be more informed and motivated to do their best in order to achieve better results and performances. As future plans, to be sure that this software has the desired results after the implementation we would like to select a group of students in order to test the application and provide us their point of view regarding it.

\section{References}

[1] Edutech Wiki (2017 March 20). Learning Analytics [Online]. Available: http://edutechwiki.unige.ch/en/Learning_analytics

[2] Y. Lindvig (2014). Learning Analytics Future possibilities and current limitations. Swedish National Agency for Education [Online]. Available: https://www.skolverket.se/polopoly_fs/1.226009!/YngveLind vig2.pdf

[3] A. Merceron, P. Blikstein and G. Siemens (2015). Learning Analytics: From Big Data To Meaningful Data. Journal of Learning Analytics [Online]. 2(3). Available: http://epress.lib.uts.edu.au/journals/index.php/JLA/article/view/4814/5175
[4] M. A. Chatti (2014). Learning Analytics: Challenges and Future Research Directions. Eleed e-learning \& education [Online]. $10 . \quad$ Available: https://eleed.campussource.de/archive/10/4035

[5] S. Powell and S. MacNeill (2012). Institutional Readiness for Analytics. Analytics Series [Online]. 1(8). Available: http://publications.cetis.org.uk/wp-content/uploads/2012/12/Institutional-Readiness-for-Analytics-Vol1-No8.pdf

[6] D. Gašević and M. Pechenizkiy (2016). Let's Grow Together: Tutorials on Learning Analytics Methods. Journal of Learning Analytics [Online]. 3(3). Available: http://epress.lib.uts.edu.au/journals/index.php/JLA/article/view/5298/5751

[7] D. Gašević, S. Dawson and G. Siemens, Let's not forget: Learning analytics are about learning, TechTrends, vol. 59, no. 1, pp. 64-71, 2015.

[8] B. Iancu (2015). A Trivia like Mobile Game with Autonomous Content That Uses Wikipedia Based Ontologies. Informatica Economică Journal [Online], 19(1). Available: http://revistaie.ase.ro/content $/ 73 / 02 \% 20$ \%20Iancu.pdf

[9] Jersey Official Site [Online]. Available: https://jersey.java.net/

[10] Wikipedia (2017 April 2). Web service [Online]. Available: https://en.wikipedia.org/wiki/Web_service

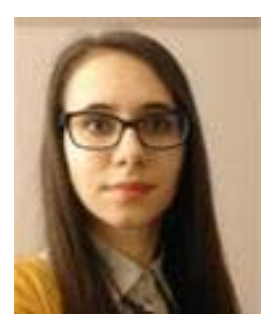

Anca IANCU has graduated the Faculty of Cybernetics, Statistics and Economic Informatics in 2015. She is currently enrolled in the Economic Informatics Master program at the Bucharest University of Economic Studies and she is also working as a Java Software Developer. Her research interests are: data mining, machine learning, speech analysis, e-learning. 


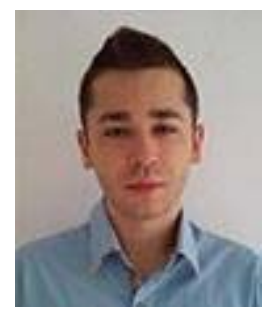

Daniel-Mihai IONESCU has graduated the Faculty of Cybernetics, Statistics and Economic Informatics in 2015. Currently he studies at the Bucharest University of Economic Studies in the Economic Informatics Master program and he is also working as a .NET Developer. His fields of interest include web programming, data structures, e-learning. 